\title{
Association between a Polymorphism of the 5-HT2C Receptor and Weight Loss in Teenage Girls
}

\author{
Lars Westberg, B.Sc., Jessica Bah, B.Sc., Maria Råstam, M.D., Ph.D., \\ Christopher Gillberg M.D., Ph.D., Elisabet Wentz, M.D., Ph.D., Jonas Melke, M.Sc., \\ Monika Hellstrand, B.Sc., and Elias Eriksson, Ph.D.
}

Receptors of the 5-HT2C subtype are assumed to be involved in the influence of serotonin on food intake. A polymorphism in the coding region of the gene for this receptor, resulting in a cysteine to serine substitution, has been reported. Fiftyseven somatically healthy teenage girls displaying weight loss and 91 normal-weight girls of the same age, all recruited by means of a population-based screening study, were compared with respect to this polymorphism. Subjects in the weight loss group displayed a higher frequency of the serine allele than those in the comparison group $(23.7 \%$ vs. $7.7 \%, p=.0001)$.
Seventy-two percent of the weight loss girls fulfilled the diagnostic criteria of anorexia nervosa, whereas $28 \%$ did not; when these two groups were separately analyzed, both differed significantly from controls with respect to serine allele frequency. The results support the notion that the studied gene may be involved in the regulation of food intake in young women.

[Neuropsychopharmacology 26:789-793, 2002] (C) 2002 American College of Neuropsychopharmacology. Published by Elsevier Science Inc.
KEY WORDS: Anorexia nervosa; Eating disorder; Serotonin; 5-HT2C receptor; Genetics; Polymorphism

Data from family and twin studies suggest that genetic factors may contribute to the development of eating disorders such as anorexia nervosa (AN) (Holland et al. 1988; Gorwood et al. 1998; Lilenfeld et al. 1998; Bulik et al. 2000; Strober et al. 2000; Kortegaard et al. 2001). As

From the Departments of Pharmacology (LW, JB, JM, MH, EE), and Child and Adolescent Psychiatry (MR, CG, EW), Göteborg University, Göteborg, Sweden.

Address correspondence to: Lars Westberg, Department of Pharmacology, Göteborg University, P.O.B. 431, SE 40530 Göteborg, Sweden, Tel.: +46-31-773 3413, fax: +46-31-821085, E-mail: lars.westberg@pharm.gu.se

Received May 9, 2001; revised November 19, 2001; accepted November 21, 2001.

Online publication: $11 / 26 / 01$ at www.acnp.org/citations/ Npp112601210. yet, no consistent findings regarding associations between specific candidate genes and eating behavior have however been reported.

Serotonin appears to exert an important inhibitory influence on food intake in experimental animals, and serotonin-facilitating compounds are known to reduce food intake also in humans (Leibowitz and Alexander 1998). An involvement of serotonin in the pathophysiology of AN gains support from the observations of altered cerebrospinal fluid serotonin metabolite levels (Gillberg 1983; Kaye et al. 1984; Kaye and Weltzin 1991) and abnormal hormonal responses to serotonergic probes (Brewerton and Jimerson 1996; Goodwin et al. 1989; Hadigan et al. 1995; Monteleone et al. 1998; Ward et al. 1998; see also O'Dwyer et al. 1996) in AN subjects, as well as from the fact that treatment with serotonin reuptake inhibitors may prevent relapse in weight-restored AN subjects (Kaye et al. 1998; Mayer and Walsh 1998; Kaye et al. 2001). 
Pharmacological studies in rats (Dourish et al. 1989; Kennett and Curzon 1991), and experiments using knockout mice (Tecott et al. 1995), suggest that the influence of serotonin on food intake is partly mediated by $5-\mathrm{HT} 2 \mathrm{C}$ receptors. This notion gains support from the observation that weight gain is a common side-effect of antidepressant and antipsychotic drugs acting as antagonists at 5-HT2C receptors, and by preliminary data suggesting that 5-HT2C-blocking compounds may be effective for the treatment of AN (Goldberg et al. 1979; Halmi et al. 1986; La Via et al. 2000). Of interest in this context is also the finding that dieting may increase 5-HT2C receptor responsiveness in humans (Cowen et al. 1996). Previous studies have suggested that AN may be associated with a polymorphism in the gene coding for another 5-HT2 receptor-the 5-HT2A subtype-but subsequent studies on this issue have yielded conflicting data (Collier et al. 1997; Ziegler et al. 1999). With respect to a possible relationship between the 5-HT2C receptor gene and $\mathrm{AN}$, the literature is as yet sparse.

The 5-HT2C receptor gene is located on the X chromosome, at q24, and contains a single nucleotide polymorphism, resulting in a cysteine to serine substitution at position 23 (cys23ser) of the receptor (Lappalainen et al. 1995). The aim of this study was to examine the possible association between this polymorphism and weight loss (regardless of underlying diagnosis) in teenage girls.

\section{METHOD}

\section{Subjects}

The original purpose of this investigation was to establish the rate of AN in 16-year-old girls in Göteborg, and to compare AN girls and age-, sex-, and school-matched controls with respect to family background, personality traits, early development, co-morbidity, and certain biological markers. To this end, a community screening was conducted in 1985 comprising all individuals in Göteborg born in $1970(n=4291)$; moreover, by means of referral, additional subjects from the community of the same age or younger also were included in the study. Assignment of subjects for further study was based on growth charts as well as on an eight-item questionnaire covering food- and weight-related issues as well as menstruations. As reference when examining individual growth charts, growth data from a normal population published by Karlberg et al. (1976) were used. To be the subject of further study, the girls had to meet one of several criteria raising suspicion of possible AN; for details, see previous publications (Rastam et al. 1989; Rastam 1992). By means of this procedure, blood samples were obtained from 58 girls displaying weight reduction not explained by somatic illness, defined as a real or projected weight loss of at least $10 \%$. Most girls were 16 or 17 years old; some of those recruited by means of referral were a few years younger. The girls were subjected to a structured interview comprising a checklist of the DSMIII-R criteria for AN (Rastam et al. 1989; Rastam 1992). A majority but not all of the subjects met the criteria of AN (see Results), including a real or projected weight loss of $15 \%$. For the genetic investigation presented in this paper, two groups of weight loss girls were hence included: those meeting the DSM-III-R criteria of AN $(n=41)$, and those reporting real or projected weight loss of $10 \%$ or more without meeting AN criteria (WL group) $(n=17)$, respectively. Some but not all of the WL girls were underweight; the inclusion criterion hence was rapid real or projected weight loss rather than low body weight. As controls to the AN and WL groups, the corresponding number of girls of the same age and in the same schoolin most cases born within a month of the index childwere identified by school nurses; furthermore, to enlarge the control group, a number of additional normal-weight 16-year-old girls also identified by school nurses were recruited. To be enrolled as a control subject, the girl had to display a completely normal weight curve and report no signs of abnormal eating behavior at interview. Almost all subjects invited to participate as controls agreed to do so. The total number of controls from which blood samples were available was 93 .

Genotyping was not part of the original research plan, but could be undertaken due to the fact that serum had been saved. DNA extraction and genotyping was successful in 57 out of 58 weight loss subjects and in 91 out of 93 controls. Forty-one of the genotyped underweight girls $(72 \%)$ fulfilled the diagnostic criteria of AN in DSMIII-R; of these, 28 (68\%) were of the restrictive type and $13(32 \%)$ of the binge-eating/purging type. The mean body mass index (BMI) $( \pm \mathrm{SD})$ of the AN subjects was $15 \pm 2$. Of the 16 genotyped WL girls, displaying weight loss but not meeting AN criteria, eight did not meet criteria for any psychiatric disorder, three had depression, three had bulimia nervosa, and two had overanxious disorder. The mean body mass index (BMI) $( \pm S D)$ of the WL subjects was $18 \pm 3$. A detailed analysis of ethnical background was not undertaken, but in a vast majority $(>90 \%)$ of both patients and controls, both parents were of Caucasian origin.

All subjects had provided informed consent to participate in the epidemiological study, but had not been informed of the fact that serum samples might be used for genotyping. For this reason, all serum samples were de-identified before genotyping, so that genotype could not be linked to identity. This procedure was approved by the ethical committee at the Göteborg University.

\section{Genotyping}

DNA was isolated from serum samples using the EasyDNA kit (Invitrogen). Genotyping was performed using the protocol described by Lappalainen et al. (1995). 


\section{RESULTS}

Subjects reporting weight loss (AN plus WL) differed from controls with respect to genotype frequency $\left(\chi^{2}=\right.$ $16.8, p=.0002)$ as well as with respect to total number of ser23 alleles in the two groups (allele frequency) $\left(\chi^{2}=14.5, p=.0001\right)$ (see Table 1$)$. A chi-square test regarding controls, $\mathrm{AN}$, and $\mathrm{WL}$ as three separate groups also revealed a significant difference between the groups, both with respect to genotype frequency $\left(\chi^{2}=\right.$ $18.1 ; p=.001)$ and with respect to allele frequency $\left(\chi^{2}=\right.$ $15.1 ; p=.0005)$. In addition, analyzed separately, both the AN group and the WL group were found to differ from controls with respect to genotype frequency (AN: $\chi^{2}=13.4, p=.001$; WL: $\chi^{2}=10.0, p=.002$ ) as well as with respect to allele frequency (AN: $\chi^{2}=12.4, p=$ .0004; WL: $\left.\chi^{2}=8.8, p=.003\right)$. AN subjects of the restrictive type did not differ from those of the binge eating/ purging type with respect to genotype frequency (data not shown).

\section{DISCUSSION}

The frequency of the ser23 allele of the 5- $\mathrm{HT} 2 \mathrm{C}$ receptor gene was higher in a group of teenage girls reporting weight loss, identified by means of a population-based screening investigation, than in a group of age-matched girls who were of normal weight and reporting normal eating behavior. The groups were small, but the high level of significance suggests that the results do not represent a false positive finding. The common problem of multiple testing is not relevant in the interpretation of our data since, in addition to the 5-HT2C polymorphism, only one other polymorphism (not presented here) was investigated in this group of patients. Moreover, the study was based on a strong prior hypothesis according to which the 5-HT2C receptor is involved in the regulation of eating behavior.

In previous studies, the frequency of subjects carrying one or two ser23 alleles in a normal population of women has varied between approximately 12\% (Gutierrez et al. 1996; Oruc et al. 1997) and 40\% (Cavallini et al. 1998; Burnet et al. 1999); in most studies, the fre- quency has been clearly lower than in our group of subjects reporting weight loss $(46 \%)$, but somewhat higher than in our comparison group (15\%). In a recent population-based investigation conducted at our laboratory, the frequency of the studied 5-HT2C allele was examined in a group of 27040 -year-old women, living in the same city as the patients and controls in the weight loss study. This population was recruited for another purpose than to serve as controls in this study, and will be presented in greater detail elsewhere (Baghaei et al., to be published). In this population, from which subjects with tentative eating disorder had not been excluded, the distribution of 5-HT2C alleles was the following: cys/cys: $74.4 \%$, cys/ser: $24.1 \%$, and ser/ser: $1.5 \%$ (Baghaei et al., to be published). The frequency of subjects carrying the ser23 allele, $25.6 \%$, was hence somewhat higher than in the controls of the weight loss study, but still significantly lower than in our weight loss subjects $(p=.009)$. A reason for the relatively low frequency of the ser 23 allele in the normal-weight controls in the present study could be that these subjects were carefully selected to be devoid of even mildly disturbed eating behavior.

It is noteworthy that a high frequency of the ser23 allele was observed not only in girls fulfilling the DSMIII-R criteria for AN, but also in a group of girls that reported weight loss but not fulfilling the criteria of AN. Given the small number of subjects in the group of WL girls without AN, these results should be interpreted with caution, but they do suggest that the ser 23 allele is not specifically associated with AN, but with a general proneness in young women to experience rapid weight loss due to reduced food intake.

The possible functional importance of the ser23 polymorphism remains to be established. Whereas Lappalainen et al. (1995) observed no differences between the two alleles with respect to electrophysiological responses to serotonin in transfected oocytes, a preliminary report from Sodhi et al. (1999) suggested that the ser23 allele is associated with a higher receptor expression.

Interestingly, two clinical studies suggest an influence of the ser 23 allele on eating behavior, one study in healthy controls showing an association between this allele and food intake after administration of $\mathrm{m}$-CPP (Quested et al. 1999), and another study revealing an

Table 1. Distribution of 5-HT2C genotype and allele frequencies.

\begin{tabular}{lrrrrr}
\hline & \multicolumn{3}{c}{ Genotype frequency } & & \multicolumn{2}{c}{ Allele frequency } \\
\cline { 2 - 5 } & Cys/Cys & Cys/Ser & Ser/Ser & Cys & Ser \\
\hline Underweight (all) $(\mathrm{n}=57)$ & $31(54 \%)$ & $25(44 \%)$ & $1(2 \%)$ & $76 \%$ & $24 \%$ \\
AN ( $\mathrm{n}=41)$ & $23(56 \%)$ & $17(42 \%)$ & $1(2 \%)$ & $77 \%$ & $23 \%$ \\
Underweight, not AN $(\mathrm{n}=16)$ & $8(50 \%)$ & $8(50 \%)$ & $0(0 \%)$ & $75 \%$ & $25 \%$ \\
Controls $(\mathrm{n}=91)$ & $77(85 \%)$ & $14(15 \%)$ & $0(0 \%)$ & $92 \%$ & $8 \%$ \\
\hline
\end{tabular}

$\mathrm{AN}=$ anorexia nervosa, $\mathrm{Cys}=$ cysteine allele, Ser $=$ serine allele. For levels of significance, see Results 
association between the ser23 allele and altered eating behavior in patients with Alzheimer's disease (Holmes et al. 1998). The present results, however, contrast to an earlier report (Nacmias et al. 1999), mentioning (without presenting data) a lack of association between AN and the 5-HT2C receptor polymorphism. Moreover, a study of the ser23 allele in bulimia nervosa and binge eating disorder was negative (Burnet et al. 1999), as well as a small, low-powered study on sister-pairs being discordant for AN (Karwautz et al. 2001).

The obvious limitation of the present study is the relatively low number of subjects in all the studied groups, and that we did not have access to DNA from a separate patient population that could be used for confirmation of our finding. The fact that the frequency of the ser23 allele was somewhat lower in our control population than in some previous studies also is a matter of concern. The fact that we observed an association reaching a $p$-value of .0001 between a polymorphism previously suggested to be involved in eating behavior and weight loss in young girls however does deserve attention, and indicates that further studies investigating the possible association between the ser23 allele of the 5HT2C receptor gene and proneness for weight loss-with or without underlying eating disorder should be undertaken.

\section{ACKNOWLEDGMENTS}

This study was supported by grants from the Swedish Medical Research Council (grants no. 8668 and 11251), Lundberg's Foundation, Wallenberg's Foundation, Thuring's Foundation, and Lundbeck's Foundation. We thank technicians Inger Oscarsson and Gunilla Bourghardt for skillful assistance.

\section{REFERENCES}

Brewerton TD, Jimerson DC (1996): Studies of serotonin function in anorexia nervosa. Psychiatry Res 62:31-42

Bulik CM, Sullivan PF, Wade TD, Kendler KS (2000): Twin studies of eating disorders: a review. Int J Eat Disord 27:1-20

Burnet PW, Smith KA, Cowen PJ, Fairburn CG, Harrison PJ (1999): Allelic variation of the 5-HT2C receptor (HTR2C) in bulimia nervosa and binge eating disorder. Psychiatr Genet 9:101-104

Cavallini MC, Di Bella D, Pasquale L, Henin M, Bellodi L (1998): 5HT2C CYS23/SER23 polymorphism is not associated with obsessive-compulsive disorder. Psychiatry Res 77:97-104

Collier DA, Arranz MJ, Li T, Mupita D, Brown N, Treasure J (1997): Association between 5-HT2A gene promoter polymorphism and anorexia nervosa. Lancet 350:412

Cowen PJ, Clifford EM, Walsh AE, Williams C, Fairburn CG (1996): Moderate dieting causes 5-HT2C receptor supersensitivity. Psychol Med 26:1155-1159
Dourish CT, Clark ML, Fletcher A, Iversen SD (1989): Evidence that blockade of post-synaptic 5-HT1 receptors elicits feeding in satiated rats. Psychopharmacology (Berl) 97:54-58

Gillberg C (1983): Low dopamine and serotonin levels in anorexia nervosa. Am J Psychiatry 140:948-949

Goldberg SC, Halmi KA, Eckert ED, Casper RC, Davis JM (1979): Cyproheptadine in anorexia nervosa. Br J Psychiatry 134:67-70

Goodwin GM, Shapiro CM, Bennie J, Dick H, Carroll S, Fink G (1989): The neuroendocrine responses and psychological effects of infusion of L- tryptophan in anorexia nervosa. Psychol Med 19:857-864

Gorwood P, Bouvard M, Mouren-Simeoni MC, Kipman A, Ades J (1998): Genetics and anorexia nervosa: a review of candidate genes. Psychiatr Genet 8:1-12

Gutierrez B, Fananas L, Arranz MJ, Valles V, Guillamat R, van Os J, Collier D (1996): Allelic association analysis of the 5-HT2C receptor gene in bipolar affective disorder. Neurosci Lett 212:65-67

Hadigan CM, Walsh BT, Buttinger C, Hollander E (1995): Behavioral and neuroendocrine responses to metaCPP in anorexia nervosa. Biol Psychiatry 37:504-511

Halmi KA, Eckert E, LaDu TJ, Cohen J (1986): Anorexia nervosa. Treatment efficacy of cyproheptadine and amitriptyline. Arch Gen Psychiatry 43:177-181

Holland AJ, Sicotte N, Treasure J (1988): Anorexia nervosa: evidence for a genetic basis. J Psychosom Res 32:561-571

Holmes C, Arranz MJ, Powell JF, Collier DA, Lovestone S (1998): 5-HT2A and 5-HT2C receptor polymorphisms and psychopathology in late onset Alzheimer's disease. Hum Mol Genet 7:1507-1509

Karlberg P, Taranger J, Engstrom I, Karlberg J, Landstrom T, Lichtenstein $\mathrm{H}$, Lindstrom B, Svennberg-Redegren I (1976): I. physical growth from birth to 16 years and longitudinal outcome of the study during the same age period. Acta Paediatr Scand (Suppl 258):7-76

Karwautz A, Rabe-Hesketh S, Hu X, Zhao J, Sham P, Collier DA, Treasure JL (2001): Individual-specific risk factors for anorexia nervosa: a pilot study using a discordant sister-pair design. Psychol Med 31:317-329

Kaye W, Gendall K, Strober M (1998): Serotonin neuronal function and selective serotonin reuptake inhibitor treatment in anorexia and bulimia nervosa. Biol Psychiatry 44:825-838

Kaye WH, Ebert MH, Raleigh M, Lake R (1984): Abnormalities in CNS monoamine metabolism in anorexia nervosa. Arch Gen Psychiatry 41:350-355

Kaye WH, Weltzin TE (1991): Serotonin activity in anorexia and bulimia nervosa: relationship to the modulation of feeding and mood. J Clin Psychiatry 52(Suppl):41-48

Kaye WH, Nagata T, Weltzin TE, Hsu LK, Sokol MS, McConaha C, Plotnicov KH, Weise J, Deep D (2001): Doubleblind placebo-controlled administration of fluoxetine in restricting- and restricting-purging-type anorexia nervosa. Biol Psychiatry 49:644-652

Kennett GA, Curzon G (1991): Potencies of antagonists indicate that 5-HT1C receptors mediate 1- (chlorophenyl)piperazine-induced hypophagia. Br J Pharmacol 103:2016-2020 
Kortegaard LS, Hoerder K, Joergensen J, Gillberg C, Kyvik KO (2001): A preliminary population-based twin study of self-reported eating disorder. Psychol Med 31:361365

La Via MC, Gray N, Kaye WH (2000): Case reports of olanzapine treatment of anorexia nervosa. Int J Eat Disord 27:363-366

Lappalainen J, Zhang L, Dean M, Oz M, Ozaki N, Yu DH, Virkkunen M, Weight F, Linnoila M, Goldman D (1995): Identification, expression, and pharmacology of a Cys23-Ser23 substitution in the human 5-HT2c receptor gene (HTR2C). Genomics 27:274-279

Leibowitz SF, Alexander JT (1998): Hypothalamic serotonin in control of eating behavior, meal size, and body weight. Biol Psychiatry 44:851-864

Lilenfeld LR, Kaye WH, Greeno CG, Merikangas KR, Plotnicov K, Pollice C, Rao R, Strober M, Bulik CM, Nagy L (1998): A controlled family study of anorexia nervosa and bulimia nervosa: psychiatric disorders in firstdegree relatives and effects of proband comorbidity. Arch Gen Psychiatry 55:603-610

Mayer LE, Walsh BT (1998): The use of selective serotonin reuptake inhibitors in eating disorders. J Clin Psychiatry 59:28-34

Monteleone P, Brambilla F, Bortolotti F, La Rocca A, Maj M (1998): Prolactin response to d-fenfluramine is blunted in people with anorexia nervosa. $\mathrm{Br} \mathrm{J}$ Psychiatry 172:439-442

Nacmias B, Ricca V, Tedde A, Mezzani B, Rotella CM, Sorbi $S$ (1999): 5-HT2A receptor gene polymorphisms in anorexia nervosa and bulimia nervosa. Neurosci Lett 277:134-136

O'Dwyer AM, Lucey JV, Russell GF (1996): Serotonin activity in anorexia nervosa after long-term weight restoration: response to D-fenfluramine challenge. Psychol Med 26:353-359
Oruc L, Verheyen GR, Furac I, Jakovljevic M, Ivezic S, Raeymaekers P, Van Broeckhoven C (1997): Association analysis of the 5-HT2C receptor and 5-HT transporter genes in bipolar disorder. Am J Med Genet 74:504-506

Quested DJ, Whale R, Sharpley AL, McGavin CL, Crossland N, Harrison PJ, Cowen PJ (1999): Allelic variation in the 5-HT2C receptor (HTR2C) and functional responses to the 5-HT2C receptor agonist, m-chlorophenylpiperazine. Psychopharmacology (Berl) 144:306-307

Rastam M, Gillberg C, Garton M (1989): Anorexia nervosa in a Swedish urban region. A population-based study. Br J Psychiatry 155:642-646

Rastam M (1992): Anorexia nervosa in 51 Swedish adolescents: premorbid problems and comorbidity. J Am Acad Child Adolesc Psychiatry 31:819-829

Sodhi M, Kerwin R, Campbell I, Makoff A (1999): A pharmacological study of variant $5-\mathrm{HT} 2 \mathrm{C}$ receptor proteins. Mol Psychiatry 4(Suppl 1):94

Strober M, Freeman R, Lampert C, Diamond J, Kaye W (2000): Controlled family study of anorexia nervosa and bulimia nervosa: evidence of shared liability and transmission of partial syndromes. Am J Psychiatry 157:393-401

Tecott LH, Sun LM, Akana SF, Strack AM, Lowenstein DH, Dallman MF, Julius D (1995): Eating disorder and epilepsy in mice lacking 5-HT2c serotonin receptors. Nature 374:542-546

Ward A, Brown N, Lightman S, Campbell IC, Treasure J (1998): Neuroendocrine, appetitive and behavioural responses to d-fenfluramine in women recovered from anorexia nervosa. Br J Psychiatry 172:351-358

Ziegler A, Hebebrand J, Gorg T, Rosenkranz K, Fichter M, Herpertz-Dahlmann B, Remschmidt H, Hinney A (1999): Further lack of association between the 5-HT2A gene promoter polymorphism and susceptibility to eating disorders and a meta-analysis pertaining to anorexia nervosa. Mol Psychiatry 4:410-412 